Mr Klein has given a balanced perspective of the good and bad parts of cruising; and he documents that many significant problems - assaults, rapes, epidemics, and fatalities - still occur in the modern cruise age. Although I do not believe it is important to know how often they occur (which is difficult to ascertain given the way complaints are handled by the cruise industry), the fact that they do happen means that every passenger should have some awareness of the risk for illness, accident, assault, and fatality, however small it may be while cruising. Potential passengers should not accept the idyllic picture that is marketed by the cruise industry.

This book is organized into sections that stratify the problems at different levels. The first few chapters deal with an explanation of the cruise industry and how it is set up, including extra costs and deceptive cost claims. Much of this is understandable, because everything promoted by the cruise industry has been marked up for a captive audience. This section will benefit those who have never cruised before and will help them to be aware of the extra costs before they go.

The section on safety includes a discussion of maritime and medical hazards abroad. These chapters feature many interesting — and disquieting — anecdotes.

A chapter is devoted to the environmental impact of cruising, and Klein's statistics give sobering realization that pollution generated by cruise ships can be enormous, not including unlawful dumping. Clearly, tighter legislation can improve this. He uses examples of how Caribbean and Alaskan ports have tried to minimize this impact by placing limitations on the cruise industry's rapid growth.

Perhaps the most relevant chapter deals with the employees: the cruise department (entertainers), support staff, deckhands, stewards, officers, and others. Klein gives a brief overview of the problems facing many of these individuals, who are overworked, underpaid, and often unable to speak to other people. It is clear that the cruise industry is able to make vacation trips affordable based on the subminimal wages paid to the employees.

This book does a great job of identifying many important issues to consider. Mr. Klein remains an enthusiast of cruising and states many times that he would like conditions to improve and then he would resume cruising. He has offered suggestions for how the industry might be improved for the benefit of all, including disabling flags of convenience (ship registration in countries like Panama or Liberia that allow lower standards), stricter central dumping, standardized medical training for doctors and nurses, and increased public awareness of problems that cruising creates.

Cruise Ship Blues is a good introduction to the microcosm of the cruising industry and is very sincere in its efforts to improve conditions by opening a forum on the author's Web site: www.cruisejunkie.com. I would recommend this book for casual readers, prospective employees, and medical professionals, as well as travel agents who advise travelers. It is very well referenced for readers wishing more background on the topics introduced. The comments I have made do not reflect any deficiency of the book but relate more to my own observations from a longitudinal relationship with the crew members as opposed to the episodic vacationer.

Cruise Ship Blues concludes that with better guidelines and training, stricter supervision by outside agencies, and appropriate sanctions when violations occur, the cruise ship industry may be able to reform itself and even become an environmental leader, if it can first be forced to recognize its deficiencies by public pressure.

$$
\begin{array}{r}
\text { Gary Podolsky, MD } \\
\text { Winnepeg, Manitoba, Canada }
\end{array}
$$

\section{The Health Instructor's Handbook, 4th edition}

Edward T. Howley and B. Don Franks

Hong Kong: Human Kinetics, 2003

US $\$ 59.00,573$ pages, hardcover

The Health Fitness Instructor's Handbook is an exhaustive resource for the health fitness instructor seeking certification and contains the most recent protocols of the American College of Sports Medicine. With dimensions of 9 by 11.25 by 1.5 inches, this behemoth could serve as a handbook for Arnold Schwarzenegger and few others. In the past, this tome has served as the textbook for University of Illinois (Champaign) Human Kinetics courses.

The format is like that of a typical textbook with a subject introduction, case examples, and study questions at the end of each chapter. Topics covered range from evaluating a person's health status, body composition, and nutrition to creating exercise plans for people of varying abilities. For example, there are chapters devoted to the diabetic, the asthmatic, and the person with "coronary heart disease." Each is quite simplistically written. There are detailed sections on calculating body fat and $\mathrm{VO}_{2}$.

The section on how to deal with medical emergencies contains information on recognizing and treating certain medical conditions. It is written at the level of a college student. The basic instructions on management of heat stroke recommend cooling as quickly as possible by packing in ice, which is not currently advised. (It is better to pack in cool, wet towels.) An entire chapter is devoted to the care and rehabilitation of the lower back, 
showing that this is one of the most common sources of disability in the United States today.

There is also an exercise section on isolation of specific muscle groups. Although the descriptions include helpful photographs on proper techniques, there is only 1 description per exercise, so the complete movement from start to finish is not visualized.

A very helpful component of this textbook is the inclusion of sample health questionnaires, consent forms, emergency procedures forms, treadmill exercise forms, sample contracts for hiring employees, and monthly budget reports. It appears to contain every resource needed to open an exercise facility.

Although this "handbook" contains a vast amount of information, each topic is given a cursory look, and it is written in a typical textbook fashion, which makes it unwieldy and dry. I believe it would serve as the perfect resource for the physical therapist seeking certification or opening an exercise facility. It has little applicability for the practitioner of wilderness and environmental medicine.

Karin H. Molander Palo Alto, CA, USA

\author{
Atlas of Travel Medicine and Health \\ Jane Chiodini and Lorna Boyne \\ Hamilton, Ontario, British Columbia: Decker Inc, 2003 \\ US \$59.95, 136 pages, softcover, glossy with bicolor \\ maps \\ Includes CD-ROM.
}

Written by 2 nursing specialists in travel medicine from Glasgow, Scotland, this well-illustrated text attempts to give the traveler an overview of health concerns covering 102 countries. The book is divided into 3 sections. Section 1 covers general health information for the health professional on issues from water safety, accidents, and heat-related topics to medical insurance. Section 2, also designed for the health professional, deals with 13 travel-related health issues, including polio, dengue fever, yellow fever, and malaria. Section 3 is the atlas portion with bicolor maps of the countries covered, including immunization recommendations, health concerns as covered in section 1, malaria, and rainfall and temperature graphs for the capital cities. The accompanying CD-ROM duplicates the text in a portable document file format (which requires free installation of Acrobat reader) that enables the reader to search for a country, disease, or any text of interest. The CD booted quickly on my computer (Windows 98SE platform) without requiring additional memory, and searching was easily achieved.

The authors supply a brief list of websites related to travel medicine and appropriately add the caveat that data are likely to change rapidly and that searching online for up-to-date information before visiting a specific country or region is well advised. This is exemplified by the lack of inclusion of West Nile virus and severe acute respiratory syndrome, which have appeared since this text was written.

It is difficult to recommend this book, not only to the health professional who advises travelers to the countries listed, but also to the individual for his or her own personal use. In most cases, the information supplied is simply an overview. There are no actual recommendations for specific medication regimens for prophylaxis or treatment of the various disease processes included. Although the maps are interesting, the information on each page is redundant, and because the rainfall and temperature charts are for the capital cities only, they may not reflect the locale that the traveler may visit. Notably absent are cold-weather and altitude concerns. The book may be appropriate as a reference for the lay traveler in order to stimulate other more in-depth inquiries to other text sources or travel-medicine specialists. The ready access in this country to online information, however, may not justify the $\$ 60$ price of the book.

John R. Saucier, MD Yarmouth, ME, USA 